\title{
THE SOI MODEL OF LEARNING: BRIDGING COGNITIVE PROCESSES OF KNOWLEDGE CONSTRUCTION IN DISRUPTIVE ERA
}

\author{
Dwi Winarsih \\ dwiwinarsih@untidar.ac.id \\ Tidar University
}

\begin{abstract}
Due to the fact that Faculty of Teacher Training and Education (FTTE) has to prepare students to be competent teachers by engaging their knowledge with current demands and to conduct their tasks ethically in teaching practice, this study reveals a report of qualitative study that employs an action and qualitative study that explore how the SOI model of learning bridging teacher students' cognitive processes of knowledge construction and their teaching competencies to face disruptive era in microteaching course. The subjects were 22 English Department students of semester 6 in a Public University who took microteaching. The qualitative data were collected in documentation, weekly-journals, observation, and video. Stimulated recall technique was also used to reflect on the video materials that they had to follow-up interviews. Data analysis shows that findings contribute significantly to understand constructivist learning occurs when a learner engages in three cognitive processes. They are first selecting or attending to relevant information about content knowledge of lesson, teaching methodology, students, curriculum, and technology, second, organizing or mentally organize information into a coherent mental representation, and third, integrating or integrate information of disruptive issues with existing knowledge of content knowledge of the lesson and teaching methodology. These improve teaching competencies of teacher students that help them to tailor and to drive instruction of TEFL. The implication shows that SOI offers a new vision of the learner as an active sense-maker to achieve adaptability skill.
\end{abstract}

Keywords: teacher student, teaching, adaptability 


\section{INTRODUCTION}

Open education provides opportunities for attracting wider participation in the creation and sharing of educational content, curriculum, and tools to address distinct needs and interests of educators and learners. In the open economy, proprietary control over educational assets and the means to organize for learning has given way to bottom-up, collective dynamics for creating educational environments and experiences.

Due to the above matters, a number of efforts have been done by educators, teachers, and students in Indonesia to enhance quality of education. These include publication and research that aim to improve and promote effective learning and teaching. However, the education system, particularly in teaching and learning English in Indonesia, remains problematic. Rote practice of teaching also becomes an obstacle to improve its quality. There is a number of publication in recent years about finding of research and its implementation in the field of education. This is an effort to promote researches that are carried out by writers and practitioners either in universities or other institutions. Besides, research aims to improve the existing conditions and achieve betterment in this disruptive era.

There are many driving forces shaping the future context of public educationincluding new discoveries in science and the diffusion of technology to demographic trends and societal issues. These are all important for understanding the context of change for education, it is important to use a critical filter on forces of change and ask where innovations emerge from these forces that will disrupt status quo structures, practices, and concepts. In particular, which disruptive innovation areas will be the source of new models, practices, and concepts that will transform the ways teachers think about teaching and learning and the kinds of people who participate in this activity?

It is now digital era that demands young generation including teachers to be multitasking ${ }^{(1)}$. Students as young generations tend to be active to explore information. Everything is accessed fast. This does not only change the way how they communicate but also how they think, behave, and utter anything to others. Internet has change the way of 
their everyday life. This affects education at schools accordingly. Thus, teachers are demanded to be flexible and good at adapting in teaching and educating them.

Referring to the facts above, student-centered learning is not applicable anymore. Teachers have to focus on students' learning activities and adapt their learning style. However, there are several teachers who get difficulties to accommodate students' interest in learning. They focus on the target of curriculum and become an agent of text-book in teaching. This problem actually concerns with teaching-learning methodology as well as students' spirit in learning. As teachers, they actually have to make the students get knowledge and have good manner lead a good life in their future.

Teacher education is relevant field of study in transferring and using research due to the fact that teaching represents a crucial profession that lead any changes in this digital era. This affects to the paradigm of teaching and learning that have shifted from "knowledge users" to "knowledge makers". ${ }^{(2)}$ The redefinition related with teachers highlights the new paradigm of education based on constructivism.

In teacher education, the facts above lead research-based course content and research-based learning of students. Besides developing research skill, teacher students might make use of the findings to provide examples of skills and knowledge to apply in teaching-learning process. Teaching is supposed to be a profession which experiences a continuous transformation and innovation process. It demands teacher education lecturers and students to be writers and knowledge users who are able to make use of their knowledge in the field of their professional fields and needs. They have to be active to be aware of complex demands in this field to meet which deals with social and cultural ones in this disruptive era.

Teacher education institution that is in charge to prepare its students to be teachers is responsible to make the students to have adaptive and effective teaching skills in teaching. Nowadays, it demands teachers to be aware how to meet students' immediate need. Besides, they have to know the facts that occur during teaching-learning process. Related with these matters, the institution is in charge to train the students to have cognitive process in order to become writers of their own professional practice in microteaching class. 
As a lecturer of microteaching, the writer is interested in preparing teacher-students to be adaptive and effective English teachers as proposed by Ion, G, Iucu, R, and PalacioVieira $\mathrm{J}$. who understand teaching theories and adapt them and technology into an efficient pedagogy in the classroom ${ }^{(2)}$. One of the writer's responsibilities is teaching a course named "Microteaching" for undergraduate Degree students majoring in English. The main objective of this course is leading the students to comprehend the principles and teaching techniques of being adaptive and effective English teaching thus as a lecturer the writer wanted to know whether SOI that stands for Selecting, Organizing, and Integrating Information. This model is supposed to be able to help teacher students in bridging their cognitive processes that are required to construct teaching materials and to experiment with their own teaching materials in the classroom in this disruptive Era. There several studies that concern with effectiveness of learning model, however this tries to reveal how SOI as a learning model affects cognitive development of teacher students as learners.

\section{REVIEW OF RELATED LITERATURE}

SOI is defined as a learning model to highlight three crucial cognitive processes in constructivist learning, $\mathrm{S}$ for selecting, $\mathrm{O}$ for organizing, and I for integrating ${ }^{(3)}$. Referring to the definition, SOI covers three elements of learning activities, i.e. selecting relevant information, organizing information, and integrating information with existing knowledge. Due to cognitive process of learners, constructivist learning concerns with activation of some cognitive processes to use incoming material and existing knowledge.

\section{Selecting Relevant Information}

Selecting relevant information is the first process. It functions to process further learning activity. Learners explore words and figures or pictures, firstly, during presentation of learning message. They have to represent them briefly in sensory memories. Naturally learners have limited capacity of human information-processing system, thus not all representations retain for further processing in working memory. Along with this matter, cognitive process of learners in selecting relevant information becomes an important one for further processing in auditory working memory. 


\section{Organizing Incoming Information}

The second process is organizing incoming information which involves organizing the selected auditory representation into a coherent verbal representation and a coherent pictorial representation. This occurs in working memory that links for example cause and effect. Learners organize incoming information which is constrained by limited amount of resources for processing by connecting or constructing appropriate relations its elements.

\section{Integrating Incoming Information}

Integrating incoming information demands learners to make one to one connections between corresponding elements of pictorial and verbal representations that they construct using their previous knowledge. The outcome of this third process is an integrated representation of the presented materials of learning. In this phase, learning process is encoding that covers mental representation to construct in working memory for long-term memory of permanent retention. This concept is in line with constructivist that views learning and emphasizes on the role of cognitive processes to build knowledge in working memory, i.e. selecting, organizing, and integrating.

\section{METHODOLOGY}

This study is an action research that employs qualitative and qualitative data analysis. It was conducted in the writer's classroom to train teacher-students to construct teaching materials and experiment them with their peers as learners. The training took place in April to June 2018 at a Faculty of Education and Teacher Training in a state university, Indonesia.

There were 20 students in this study, three students were male while seventeen others were female ones. They were majoring in English educational. This study employed instruments that were designed to explore students' opinions about their peer teaching practice that is assumed to be learning-by-doing to choose teaching methodology and teaching materials. Besides, they have to reflect on their teaching experience and reviewing their classmates' practical teaching. Additional research qualitative data was derived from group feedback.

Procedures of action consist of preparation, teaching practice, and self and group reflection. Step one is preparation. The writer-lecturer provided the teacher-students with 
knowledge of theories and teaching techniques that were adopted from current curriculum or English lesson curriculum of 2013 as well as the steps of teaching. How to adapt or create teaching materials was introduced. In this step, students were asked to investigate how to teach English from the related texts and other resources.

The second step was teaching practice. The students were asked to adapt their knowledge to construct teaching materials focusing on teaching techniques which they prefer to adopt. They also presented their teaching materials to the writer and classmates. The students brainstormed good points and bad points, comments and suggestions to improve the materials. The improved materials were then given to the lecturer to check their effective teaching of English. Finally, they experimented with their teaching at microteaching class. Each teacher-student taught two English classes which were 40 minutes per class and their friend behaved as students. Group work was handled during the first class while individual work was employed in the second class.

Step 3 covers self and peer reflection. After finishing class, the teacher-students had to complete the available research instrument to reflect on teaching practice and experience. The peers reviewed and discussed weaknesses and strengths of their practical experience as well as offered suggestions to improve their teaching competencies.

\section{Data Analysis}

Based on data of questionnaire on 'do you like the learning model?' 18 students answered that they like it very much. Only two of them did not like to enjoy it because they were not ready to do the all assignment in micro teaching. These two students saidas the following.

"sorry .... I am not ready to reorganized my teaching design, because I just wait for your comment ma'am"

These two students seemd to be passive in learning. While the other 18 students express their ideas as the following excerpt

“ thanks Ma'am you let me reflect on my teaching, so I know my weaknesses and my strengthes. I know about my teaching methodology, teaching media, and my classroom management" 
Based on those data, the teacher students enjoyed and liked the well-planned steps of SOI model which began with selecting available technology, theories and teaching techniques using the current English curriculum or curriculum 2013 which uses text-based teaching through listening to lectures, watching videos, investigating by themselves and brainstorming in the group. Then they experienced cognitive process to organize and integrate knowledge which they gained for constructing the teaching materials and experimented in microteaching classroom.

The teacher students worked in groups to lead processes of learning by doing SOI model to improve their teaching materials and skills. They explained that language teaching theories are needed to provide appropriate concepts of what to teach, how to teach, and teaching techniques. They thought the lecturer encourage them to focus on the most relevant information. This selecting process helped them to know the teaching theories and helped them adapt the materials to the actual level of the learners in the classroom. They also benefited from the presentation of teaching materials between them and their peers either in group or class.

Listening to various comments made them understand how to improve his teaching materials and skills. The 10 students said that they felt more confident in organizing and constructing English teaching materials after group brainstorming. Brainstorming helped teacher students to organize incoming information into a coherent mental representation that functions to support creative problem solving. At the end of the program, almost all students expressed that SOI model helped them to activate, use their prior knowledge, and coordinate multiple representations of materials. Only two of them got difficulties to adapt their prior knowledge and nowadays demand of disruptive era.

Nine students revealed that SOI model helped them discover how to teach by themselves. They were not satisfied with their initial teaching performance working in groups. They realized that the input in her teaching plan were not suitable with learners' capacity. They recognized that the learners had difficulties and were bored with the class. Most of them were looked neglect learning activities that were organized by the teacher students. 
During the brainstorm after teaching, they felt that her misunderstanding could be checked and clarified. She also realized that she needed to improve their teaching materials and aids for the next class to be more appropriate to learners' capacity. The analytical comments and creative suggestions from the group discussion helped them improve their effective teaching. They also explained how listening to a lecturer by a specialist inspired them to investigate the task-based approach more thoroughly. This led them to realize that learner-centered activities that focus to employ teacher students' capacity should be used in the classroom. The learners will be more active in participating with the teacher and their friends.

SOI model also helped another teacher-student realized that his teaching level was higher than the students' ability in their first class. They analyzed that the teacher students' potential changed the input to be more suitable to the students' level for his second teaching session. This experience confirms that when teacher students discover a problem they will find appropriate and effective way to solve it. Moreover, SOI model can help each teacher student to construct and discover the good and weak points of each teaching methodology.

The teaching Practice being observed in this research trained to activate cognitive process in constructing teaching materials based on the principles and teaching techniques of each methodology and the demands of disruptive era. They focused on the potentials of technology in disruptive era in teaching dialogue memorization, pronunciation, vocabulary and language structure; varieties of reading comprehension exercises; and emphasizing interaction in pairs, exchanging information in small group work, plus asking learners to produce language by themselves through spoken or written language during the communicative activities.

Some student teachers noticed that their classmates applied student-centered teaching practice more than teacher-centered one instead of student-active learning as it is required during teaching-learning process of reading class. The following excerpt shows the students comments on their friends' teaching practice.

"I think as a teacher ..... most of the time you just explain the materials by using power points and write the examples of English expression on the board you dominate the classroom interaction. 
Another student agreed with the idea and suggested as the following.

“ yes, you did not ask students to participate in your teaching. You tell students about the materials during the lesson. It is better for you to invite students to build sentences or expressions based on your explanation of rules to build English expressions"

The expression above showed that some other student teachers as observers concluded that it would be useful if they encouraged the learners to make use of their potentials such as interest and available technology to comprehend the reading passage by themselves.

\section{DISCUSSION OF FINDING}

SOI model can stimulate teacher students to think and create their own teaching materials and organize their teaching in classroom. This finding is based on the results of informal interviews with the student which is presented as the following. 15 of them said that it was the first time for them to produce English teaching materials. All 20 of them were proud that they were able to create teaching materials through their own practice and understanding of their incoming materials of teaching and their previous knowledge. Thus, these analysis and finding are supported by the concept of constructivism. Here, the teacher students employ knowledge construction approach in which instructional designs that were prepared by students were based on several underlying values about the appropriate goals of instruction, including a focus on process as well as product, on transfer as well as retention, and how to learn as well as what to learn. Referring to Benjamin Bloom who pioneered Bloom's Taxonomy in 1956, higher thinking in education covers analyzing, applying, evaluating, or creating. These aspects should be emphasized rather than just remembering lesson materials and facts that is called rote learning ${ }^{(4)}$. This is confirmed by constructivist concept which is based on the idea that there is value of considering what goes on inside the learners' head rather than considering only what is presented. In other words, learning from experiences results directly from one's actions ${ }^{(3)}$. The process of learning is a central value of constructivist approach.

SOI model integrated with group brainstorming and feedback which helps teacher students to improve their teaching skills. Brainstorming in a group discussion generated feedback on the students' teaching performances and what needed to be improved. The 
teacher students are able to use what they have learned and others' comments or feedback rather than simply to be able to remember them. All 20 students stated that comments from the writer-lecturer and classmates were very useful. Besides, this demands them to adapt their knowledge, beliefs, and existing condition. They can use the comments to improve their teaching. Teaching is characterized experience of change, novelty, and uncertainty. This evidence confirms that understanding critical feedback and adopt them in teaching practice are the main elements in cognitive process of constructivism. Deep understanding is the ability to transfer what has learned to novel situation, so the constructivist highlights measures of learning that go beyond retention. Motivating values of constructivist is that meaningful learning is often preferable to rote learning and deep understanding than memorization.

This can help students gradually gain the skill of adaptability and the skill of teaching or being competent teacher. It is integrated with the reflective technique that assists teacher students to improve their effective teaching. The students stated selfreflection and peer reflection contributed them to have improvement in efficient teachinglearning activities. It helps them to activate and use prior knowledge and to activate and coordinate multiple representations of the teaching materials and methodology. A research demonstrates how to use advance organizer, illustration, worked-out examples, and elaborative questions to foster knowledge integration ${ }^{(5)}$. It can stimulate teachers to think what happens in the classroom. This encouraged getting alternative means to achieve learning objectives and consideration the teaching-learning activities tactfully, thoughtfully, and analytically. These, of course, are needed to adjust lesson, classroom management, and seeking new resources to respond unexpected situation. This supports an opinion that instruction techniques for promoting active cognitive processing, constructivist learning depends on the learners' beliefs ${ }^{(6)}$. Similarly, people learn best when they are personally involved in the learning experience ${ }^{(7)}$. Knowledge has to be discovered by an individual if it is to have any significant meaning or make a difference in their behavior.

The writer discovered that the teacher students benefit from three major components: selecting, organizing, and integrating. This SOI model encourages teacher students to discover knowledge and skills by themselves. A saying says, "I hear and I 
forget. I see and I remember. I do and I understand" ${ }^{(8)}$. Teacher students can develop their teaching when they have chances to talk about their real teaching issues. Brainstorming can provide students the opportunity to discuss what happened in their classroom by selecting, organizing, and selecting. Vygotsky states that knowledge can be constructed through interactions between people in relation to the world as well as through the distance between the actual developmental level and potential development. It is determined by students' independent problem solving and their level of potential development under guidance of adults or collaboration with more capable friends or peers ${ }^{(9)}$. The writer thinks that more experienced people can help raise students to the level of their potential development.

It is better if teachers have time to think or reflect on what they have done in the classroom and adapt the demand of teaching in this disruptive era that changes often happens. Hence, three major components of learning in microteaching class by selecting, organizing, integrating should be taken into consideration if one wants a model of the efficient format of effective teaching for training teacher students skill of teaching English.

\section{CONCLUSIONS AND RECOMMENDATIONS}

SOI model was used efficiently with 20 teacher students of undergraduate degree in this investigation. It helped the students gain adaptability and teaching skill in microteaching class. Practical teaching with peers in microteaching activities also assisted them to comprehend the real problems in the classroom. They learned how to select material, organize material and activities, and integrate them in effective teaching. They practiced to solve the problems such as adjusting the existing demand in disruptive era and level of their teaching materials to suit the learners' ability.

This research proves that it is possible to design instruction that promotes constructivist learning, when learners are engaged in a behaviorally active learning. SOI model of learning in microteaching class help teacher students in Bridging Cognitive Processes of Knowledge Construction in Disruptive Era. The teaching techniques of brainstorming in a group discussion and the reflective technique are also vital components in the cycle of selecting, organizing, and intergrating. Constructivist learning occurs when the teacher students engage three cognitive process of learning, i.e. attending relevant 
information, mentally organizing the information into coherent representation, and integrating the information with existing knowledge.

SOI model of learning enhances teacher students' learning and teaching experience in disruptive era. It emphasizes a student-centered approach. They are active throughout the learning process. Due to the process of social interaction during teaching practice which cover planning the lesson and practice it in microteaching, each teacher student has an opportunity to design teaching-learning materials, media, and methodology. Thus, discovering knowledge and experience result gradual improvement of teaching competencies.

Constructivist offers teacher students to be active sense-maker and emphasizes hands-on activity and discussion about their knowledge, beliefs, and the demands in disruptive era. Lecturers' comments or suggestions as experienced people help students to develop their teaching competencies and skills. Lecturers of microteaching should consider the cycle of vital components in the teaching and learning process. They must prepare teacher students to gain sufficient knowledge for the target task. It is also important to provide opportunities for students to perform tasks by themselves so they experience of cognitive process of knowledge construction in planning the lesson and practice it to adjust the demands of disruptive era. Thus adaptability skill and effective teaching skill are achieved successfully by the teacher students. 


\section{REFERENCES}

Kristiyanto, E. (2017). Guru Kita: Artis Karakter \& Kecerdasanu Penulis. Article. Kompas: 8 Juli 2017. Jakarta

(2) Ion, G, Iucu, R, and Palacio-Vieira J. (2014). "Research-based teaching and learning in higher education: The perspective of postgraduate students. Proceeding http://www.iced2014.se/proceedings/1575_ION_IUCU_PALACI O.pdf

(3) Reigeluth, M., C. (2009). Instructional-Design Theories and Models. New York : Routledge

(4) Krathwohl, D. D (2002): A Revision of Bloom's Taxonomy: An Overview, Theory Into Practice, 41:4, 212-218. Article: http://dx.doi.org/10.1207/s15430421tip4104_2

Mayer, E., R. (2002). Cognitive Theory and the Design of Multimedia Instruction: An Example of the Two-Way Street between Cognition and Instruction. Article. https://.org/10.1002/t1.47

Winarsih, D. (2012). Teachers' Beliefs And Their Professional Practice In Literacy-Based Instruction. Dissertation. Semarang : UNNES

Ord, J. (2012). John Dewey and Experiential Learning: Developing the theory of youth work. Journal: Youth \& Policy, 108, 55-72.

Kan, Q. (2017). What's Your Favorite Confucius Quote on Education and Learning?. Article. Retrieved from http://www.open.edu/openlearn/education/12-famousconfucius-quotes-on-education-and-learning

Smidt, S. (2009). Introducing Vygotsky. New York : Routledge 
